attributed to the excitation of a predominantly crossed occipitopretectal tract. ${ }^{3}$ Cogan stated that "removal of the pupilloconstrictor zone in one occiput of the cat results in anisocoria with the larger pupil on the opposite side".4 This finding presumably explains the unilateral pupillary dilatation reported here as a negative ictal phenomenon.

$$
\begin{array}{r}
\text { J W LANCE } \\
\text { Institute of Neurological Sciences, } \\
\text { Prince of Wales Hospital, } \\
\text { Sydney, Australia }
\end{array}
$$

Correspondence to: Professor J W Lance, Suite 5A, 66 High Street, Randwick, NSW 2031, Australia.

1 Gastaut H, Broughton R. Epileptic seizures, clinical and electrographic features, diagnosis and treatment. Springfield, IL: Charles $\mathrm{C}$ Thomas, 1972:109.

2 Taylor DC, Falconer MA, Bruton CJ Corsellis JAN. Focal dysplasia of the cerebral cortex in epilepsy. $\mathcal{F}$ Neurol Neurosur Psychiatry 1971;34:369-87.

3 Lance JW, Smee RI. Partial seizures with visual disturbance treated by radiotherapy of cavernous hemangioma. Ann Neurol 1989, 26:782-5.

4 Cogan DG. Neurology of the ocular muscles. Springfield, IL: Charles C Thomas, 1948: 115 .

Glial cytoplasmic inclusions are not exclusive to multiple system atrophy

In 1989 Papp et al ${ }^{1}$ reported finding argyrophilic inclusions in the cytoplasm of oligodendrocytes in cases of multiple system atrophy, and their presence in the sporadic form of this condition has since been confirmed. ${ }^{2}$ The value of glial cytoplasmic inclusions as a diagnostic hallmark of multiple system atrophy has been emphasised by one of the authors ${ }^{3}$ as well as by others. ${ }^{2}$

At the UK Parkinson's Disease Society Brain Bank in London, tissue is donated by patients with principally movement disorders. Glial cytoplasmic inclusions occurred in all brains from patients with multiple system atrophy (total 56); however, in three of seven cases with a pathological diagnosis of corticobasal degeneration and two of 18 cases with Steele-Richardson-Olszewsk syndrome similar intracytoplasmic oligodendrocyte inclusions were identified. These were filamentous argyrophilic structures (figure) immunoreactive with tau and

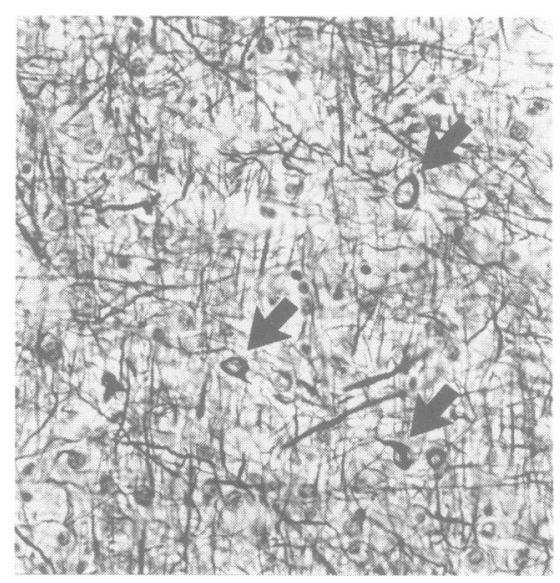

Frontal hemispheric white matter; corticobasal degeneration with argyrophilic cytoplasmic inclusions in oligodendrocytes (some arrowed) modified Bielschowsky originally $\times 400$. ubiquitin antiserum. In corticobasal degeneration they were most numerous in white matter underlying the affected cortex, in the corpus callosum, internal capsule, and in one case, the basis pedunculi; occasional similar inclusions were also identified in the affected cerebral cortex and in the brain stem as well as in cerebellar hemispheric white matter, in the absence of any neuronal abnormalities. In the cases of SteeleRichardson-Olszewski syndrome inclusions were most prominent in cerebellar white matter. We have not counted or mapped the distribution of glial inclusions in our cases, but have the impression that they are less numerous than in multiple system atrophy.

These findings have important implications for histological diagnosis and our understanding of disease pathogenesis. There is increasing awareness of overlap between many neurodegenerative conditions, in particular those associated with parkinsonism; thus the Lewy body, Pick body, neurofibrillary tangle, or the glial cytoplasmic inclusion are not exclusive to any of the conditions in which they abound. One explanation may be that neurons and glia have a limited repertoire of responses to a variety of different stimuli, resulting in morphological similarities between clinically distinct neurodegenerative diseases. Alternatively, shared pathogenetic pathways may underlie the cytoskeletal abnormalities seen in these conditions, the exact pattern of pathology being dictated by host factors such as age of exposure and genotype.

$$
\begin{array}{r}
\text { S E DANIEL } \\
\text { J F GEDDES } \\
\text { T REVESZ } \\
\text { Parkinson's Disease Society Brain Bank, } \\
\text { Institute of Neurology, } \\
1 \text { Wakefield St, London } \\
\text { WC1N 1Pf, UK }
\end{array}
$$

Correspondence to: Dr S E Daniel.

1 Papp MI, Kahn JE, Lantos PL. Glial cytoplasmic inclusions in the CNS of patients with multiple system atrophy (striatonigral degeneration, olivopontocerebellar atrophy and Shy-Drager syndrome). $\mathcal{F}$ Neurol $\mathrm{Sci}$ 1989;94:79-100.

2 Lantos PL, Papp MI. Cellular pathology of multiple system atrophy: a review. $尹$ Neurol multiple system atrophy: a review. $\mathcal{F}$

3 Daniel SE. The neuropathology and neurochemistry of multiple system atrophy. In Bannister R, Matthias CJ, eds. Autonomic failure, 3rd ed, Oxford: Oxford University Press, 1992.

\section{Is visual neglect body-centric?}

One theory of unilateral visual neglect proposes that it results from disruption of representations of space. But what exactly is the nature of the spatial map that is disrupted? Is it retinotopic, head-centric, body-centric, mapped with respect to gravity, or even possibly object centred? Many of those who have been attracted by representational hypotheses have suggested that it may be body-centric. In other words, the hemispace that patients with left sided visual neglect fail to attend to is that to the left of the body sagittal midline.

Evidence in favour of a disruption of body-centric (or socalled egocentric) spatial representation has been presented from measurements of saccadic latency to briefly illuminated targets with the head turned at various angles with respect to the trunk.' Furthermore, Heilman and Valenstein have shown that line bisection is more accurate when the task is presented to the right of the body midline. ${ }^{2}$ Cancellation tasks are another way of assessing neglect. If left sided visual neglect is body-centric there should be amelioration, or even complete absence, of neglect when the task is performed in the hemispace right of the body midline.

Eight right handed patients presenting acutely with visual neglect were examined. All of them had left sided visual neglect on the day of presentation; some also had left sided hemiplegia or somatosensory loss. None of the patients were considered to have a substantial visual field loss on clinical examination at the bedside. (Assessment of the left half of the visual field was aided by cueing attention, but not gaze, to the left. Patients were asked to fix their gaze on the author and simultaneously encouraged to say whether relatively large objects-for example, flowers - on the left were being moved. Once patients were accustomed to this task, the flowers were held stationary at the edge of the left visual field and patients were asked to keep attending towards the flowers. A hatpin was then used to map visual fields, but patients needed to be reminded constantly to attend to the left. I was eventually able to convince myself that all the patients reported here could see a moving hatpin in each quadrant of the visual field.) All eight patients had CT performed within five days of presentation. Evidence of cortical infarction involving the right parietal cortex, or frontal cortex, or both was found on all of the tomograms (table).

Each patient was asked to perform the cancellation task devised by Weintraub and Mesulam. ${ }^{3}$ Patients were first shown the target shape (a circle with eight spokes and a diagonal running through the circle) on a small piece of card. They were then presented with the task, which has 60 such targets disposed among 318 distractor shapes on an A4 sheet of paper. Thirty targets are present in each half of the sheet, so the maximum score is 60 . Patients were asked to ring all the targets visible to them. No time limit was imposed.

The task was first presented on a table directly in front of the patients so that in this condition the head and body midlines were aligned. Patients were instructed to let the experimenter know when they thought that they had completed the task. After a short break, the task was presented on the table at $45^{\circ}$ right of the body midline. Patients performed the second trial with the head turned $45^{\circ}$ to the right and the trunk held still in the original position. The table shows the results of the experiment. As expected, patients cancelled items only on the right half of the cancellation sheet (by contrast with patients with only visual field loss, who are able to cancel targets on both sides of the paper).

The mean cancellation score when head and trunk were aligned was 6.7 (SD 4.7) items; when the head was turned to the right it was 5.9 items $(S D=5 \cdot 2)$. There was no significant difference in performance between these two conditions (paired $\mathrm{t}=1 \cdot 1, \mathrm{df}=$ $14, p=0 \cdot 3$ ). Thus patients performed just 
Patient characteristics and cancellation scores

\begin{tabular}{llccc}
\hline Patient (age) & Lesion & $\begin{array}{l}\text { Days } \\
\text { after stroke }\end{array}$ & $\begin{array}{l}\text { Items cancelled } \\
\text { in front }\end{array}$ & $\begin{array}{l}\text { Items cancelled } \\
\text { in right space† }\end{array}$ \\
\hline A (70) & R parietal & 3 & 4 & 4 \\
B (66) & R parietal & 8 & 5 & 5 \\
C (86) & R parietofrontal & 2 & 16 & 18 \\
& & 10 & 2 & 1 \\
D (65) & R parietofrontal & 66 & 3 & 1 \\
E (80) & R frontal & 10 & 6 & 5 \\
& & 3 & 7 & 6 \\
F (67) & R frontal & 26 & 3 & 6 \\
G (71) & R frontal & 1 & 4 & 2 \\
H (77) & R frontal & 3 & 8 & 8 \\
\end{tabular}

*When head midline is aligned with body midline. +When head midline is turned 45 degrees to the right of body midline. as badly when the cancellation task had to be performed in the hemisphere right of the body midline. Unilateral visual neglect therefore does not seem to be body-centric.

This conclusion contradicts that of the two previous reports. ${ }^{12}$ There are at least three possible explanations. Firstly, the method employed here-a cancellation task-has never previously been used to assess the co-ordinate frame of neglect. Secondly, there is a possibility that because the sample size is small $(n=8)$, the conclusion is not representative of all patients with neglect. The same may be said, however, of the other studies cited. A third possible explanation is that the tasks used in the previous studies assessed different brain functions examined by cancellation tasks. It is not possible to say which, if any, of these explanations is correct.

Although the results of this study suggest that neglect is not body-centric, they do not exclude the general proposition that it is a deficit in representing space. It remains a possibility that the disrupted representation is mapped in another coordinate frame. Two studies have examined the pattern of visual inattention when patients are either reclined $^{4}$ or tilt their heads ${ }^{5}$ to the left or right. Both found that irrespective of head position, inattention was worse to the left of the environmental vertical. But both investigations also showed that neglect "moves with the head": patients attended less to the left of the head midline, whatever its orientation, as well as attending less to the left of the environmental vertical.

Another study investigated how patients with neglect performed on a somatosensory exploration task and also found evidence of two forms of deficit. ${ }^{6}$ One seemed to be body-centric, but the effect barely reached statistical significance; the other was mapped with respect to the "line of sight" and was more significant. It was not possible to distinguish whether the line of sight effect was due to a deficit in head-centric or retinotopic coordinates. The results of the present study would also be consistent with either a head-centric, retinotopic, or object centred deficit, but they do not support the

I thank Professor C Kennard for useful comments and criticisms.

MASUD HUSAIN

Mead Ward, Intensive Care, St Thomas' Hospital, St Thomas' Hospital,
Lambeth Palace Road Lambeth Palace Road, hypothesis that neglect is body-centric.
1 Karnath HO, Schenkel P, Fischer B. Trunk orientation as the determining factor of the "contralateral" deficit in the neglect syndrome and as the physical anchor of the internal representation of body orientation in space. Brain 1991;114:1997-2014.

2 Heilman KM, Valenstein E. Mechanisms underlying hemispatial neglect. Ann Neurol 1979;5:166-70.

3 Weintraub S, Mesulam M-M. Visual hemispatial inattention: stimulus parameters and exploratory strategies. $₹$ Neurol Neurosurg Psychiatry 1988;51:1481-8.

4 Calvanio $R$, Petrone PN, Levine DN. Left visual spatial neglect is both environmentventred and body-centred. Neurology 1987 ; 37:1179-83.

5 Ladavas E. Is the hemispatial deficit produced by right parietal lobe damage associated with retinal or gravitational coordinates? Brain 1987;110:167-80.

6 Bisiach E, Capitani E, Porta E. Two basic properties of space representation in the brain: evidence from unilateral neglect. f Neurol Neurosurg Psychiatry 1985;48:141-4.

\section{A novel cytochrome $P$-450IID6 (CYPIID6) mutant gene associated with multiple system atrophy}

Parkinson's disease and multiple system atrophy, including olivopontocerebellar atrophy and striatonigral degeneration, are characterised by pathological changes in the brain, including the basal ganglia. ${ }^{1}$

Several neurotoxins, such as 1-methyl-4phenyl-1,2,3,6-tetrahydropyridine (MTPT) and 1,2,3,4-tetrahydroisoquinoline (TIQ) can induce parkinsonism in animals. ${ }^{23}$ The poor metaboliser phenotype of debrisoquine hydroxylation was considered to be associated with susceptibility to Parkinson's disease, ${ }^{4}$ and one genomic mutation (poor metaboliser genotype) of cytochrome $P$ 450IID6 (CYPIID6, which metabolises debrisoquine and also possibly detoxifies MPTP and TIQ), has been reported to be overexpressed in Parkinson's disease. ${ }^{50}$
Furthermore, it was reported that a novel mutation from $\mathrm{Arg}^{296}$ to $\mathrm{Cys}^{296}$ located at the HhaI site in exon 6 of the CYPIID6 gene might be associated with Parkinson's disease (the mutated allele frequency was $0 \cdot 21)$.

We have analysed the CYPIID6 gene according to the method of Tsuneoka et al ${ }^{7}$ in 10 Japanese patients with multiple system atrophy (only sporadic cases; diagnostic criteria by Quinn ${ }^{8}$ ) to investigate the relation between the polymorphism of CYPIID6 and susceptibility to multiple system atrophy. There was no significant difference in the frequency of the poor metaboliser genotype between the cases and controls $(p>0.05)$. As the table shows, however, the frequency of the mutation located at the Hhal site in exon 6 in the patients $(0.45)$ was significantly higher than that in the controls $(0.09)(p<0.05)$.

These results suggest that the polymorphism of the HhaI site in exon 6 of the CYPIID6 gene may be a useful molecular marker for susceptibility to multiple system atrophy, as in Parkinson's disease, and that both diseases may have a mutual pathogenesis associated with CYPIID6, reducing defence against neurotoxic environmental factors. Further studies in a larger number of patients are necessary to confirm these preliminary findings.

KAZUHIKO IWAHASHI RYOSUKE MIYATAKE Department of Neuropsychiatry, YUTAKA TSUNEOKA YOSHINORI MATSUO YOSHIYUKI ICHIKAWA Department of Biochemistry,
KIYOSHI HOSOKAWA University Hospital, Kagawa Medical School, Kagawa, 761-01, fapan Clinical Research Institute of Clinical Research Institute of
National Sanatorium, Minamiokayama Hospital, Okayama, 701-03, fapan

Correspondence to: Dr K Iwahashi, Department of Neuropsychiatry, Kagawa Medical School, Kida-gun Miki-cho, Kagawa 761-07, Japan.

1 Oppenheimer DR. Neuropathology of progressive autonomic failure. In: Bannister $\mathbf{R}$, ed. Autonomic failure : a text book of clinical disorders of the autonomic nervous system. Oxford:

2 Yoshida $M$, Niwa $T$, Nagatsu $T$. Parkinsonism in monkeys produced by chronic administration of an endogenous chronic administration of an endogenous substance of the brain, tetrahydroisoquinoline: the behavioral and biochemical changes. Neurosci Lett 1990;119:109-13.

3 Ohta S, Tachikawa O, Makino Y, Tasaki Y, Hirobe $M$. Metabolism and brain accumulation of tetrahydroisoquinoline (TIQ), a possible Parkinsonism inducing substance, in an animal model of a poor debrisoquine metabolizer. Life Sci 1990;46:599-605.

4 Barbeau A, Cloutier T, Roy M, Plasse L, Paris $S$, Poirier J. Ecogenetics of Parkinson's disease: 4-hydroxylation of debrisoquine. Lancet 1985;ii:1213-6.

5 Armstrong M, Daly AK, Chalerton S, Bateman DM, Idle JR. Mutant debrisoquine hydroxylation genes in Parkinson's disease. hydroxylation genes in Part KEIKO SATO
TOSHIYUKI HAYABARA disorders of the autonomic nervous system.

Genotypes of the HhaI site in the CYPIID6 gene from patients with multiple system atrophy and controls

\begin{tabular}{lllll}
\hline & $\begin{array}{l}\text { Wild type } \\
\text { homozygote } \\
(w / w)\end{array}$ & $\begin{array}{l}\text { Heterozygote } \\
(w / m)\end{array}$ & $\begin{array}{l}\text { Mutant type } \\
\text { homozygote } \\
(\mathrm{m} / \mathrm{m})\end{array}$ & $\begin{array}{l}\text { Allele frequency } \\
(\mathrm{w}: \mathrm{m})\end{array}$ \\
\hline $\begin{array}{l}\text { Patients with MSA } \\
\text { Controls }\end{array}$ & 4 & 3 & 3 & $0 \cdot 55: 0 \cdot 45^{\star}$ \\
\hline
\end{tabular}

${ }^{\star} p<0.05$. Values are the numbers of patients and controls. MSA $=$ multiple system atrophy. 